Article

\title{
On the Performance and Recyclability of a Green Composite Based on AESO Resin
}

\author{
Cláudio P. Seabra ${ }^{1}$, Ana Catarina Sousa ${ }^{2,3} \mathbb{D}^{\circ}$, Ivo M. F. Bragança ${ }^{1,4,5, *}$, Carlos M. A. Silva ${ }^{4}(\mathbb{D}$, \\ M. Paula Robalo ${ }^{2,3}$, M. Amélia R. Loja ${ }^{1,4,5}$ (D) and Paulo A. F. Martins ${ }^{4} \mathbb{D}$ \\ 1 Área Departamental de Engenharia Mecânica, Instituto Superior de Engenharia de Lisboa, \\ Instituto Politécnico de Lisboa, Rua Conselheiro Emídio Navarro, 1, 1959-007 Lisboa, Portugal; \\ A40514@alunos.isel.pt (C.P.S.); amelia.loja@isel.pt (M.A.R.L.) \\ 2 Área Departamental de Engenharia Química, Instituto Superior de Engenharia de Lisboa, \\ Instituto Politécnico de Lisboa, Rua Conselheiro Emídio Navarro 1, 1959-007 Lisboa, Portugal; \\ acsousa@deq.isel.ipl.pt (A.C.S.); mprobalo@deq.isel.ipl.pt (M.P.R.) \\ 3 Centro de Química Estrutural, Instituto Superior Técnico, Avenida Rovisco Pais, 1049-001 Lisboa, Portugal \\ 4 IDMEC, Instituto Superior Técnico, Universidade de Lisboa, 1649-004 Lisboa, Portugal; \\ carlos.alves.silva@tecnico.ulisboa.pt (C.M.A.S.); pmartins@tecnico.ulisboa.pt (P.A.F.M.) \\ 5 CIMOSM-Centro de Investigação em Modelação e Optimização de Sistemas Multifuncionais, ISEL- \\ Instituto Superior de Engenharia de Lisboa, Rua Conselheiro Emídio Navarro, 1, 1959-007 Lisboa, Portugal \\ * Correspondence: ibraganca@dem.isel.pt
}

Received: 11 June 2020; Accepted: 1 July 2020; Published: 4 July 2020

check for updates

\begin{abstract}
The aims and objectives of this paper are two-fold: first to investigate the production of a green composite manufactured with renewable materials (i.e., jute fabric as reinforcement, acrylate epoxidase soybean oil (AESO) as matrix and sisal particles (SP) as filler), by the wet layup method; second, to propose a recycling procedure to recover the individual materials and reuse them in the production of a second-life composite. In the first part, different combinations of SP (0,5 and $10 \mathrm{wt} \%)$ and hardener $(2,5$ and $10 \mathrm{wt} \%)$ were mixed with AESO resin, poured into a mould, cured and submitted to mechanical and physicochemical characterizations to identify the best conditions for the composite production. Virgin green composites with $10 \mathrm{wt} \% \mathrm{SP}, 5 \mathrm{wt} \%$ hardener and 5 layers of jute fabric, capable of assuring $91 \mathrm{HA}$ of hardness and 10.6 MPa of tensile strength, were fabricated. The second part describes the recycling process of the composites with acetone, an organic solvent recommended by the safety, health and environmental criteria, to breakdown the resin matrix and recover the jute fabric reinforcement and resin particles, which were then reused to fabricate a second-life composite. Although the hardness values of the second-life composite were smaller (4\%) and the tensile strength varied with composition, the absorption of water was considerably reduced (in the range of 22 to 51\%). This last result mitigates one of the green composite's limitations and fosters circular economy by assuring the applications of the second-life composite in the field of transportations, packing and furniture, among others.
\end{abstract}

Keywords: green composite; recycling; second-life composite; natural fibres; soybean oil; mechanical properties; water absorption

\section{Introduction}

Nowadays, conventional manufacturing processes are being pushed to their limits to produce increasingly intricate parts at lower cost. If, on the one hand, this stimulates the development of new processes with conventional materials, on the other it promotes the extension of the application domain of existing processes to new types of materials. Composites are in the front line of ongoing developments to replace conventional materials in many different fields of applications, due to 
their capability of offering enhanced mechanical, physical and chemical properties with significant reductions in material weight $[1,2]$.

Since most composites are made from petroleum-based polymers and synthetic fibres, their use comes with a price of difficult recyclability and are out of alignment with the current environmental sustainability trends and requirements. In fact, the end-of-life disposal of composites contributes to increase the serious global pollution problem, particularly with regard to greenhouse emissions and toxic gases, as an outcome from incineration and permanent landfill accumulation [2-4]. All these concerns, together with the growing of environmental legislation restriction trends, results in an inevitable pressure towards the use of composites from renewable and natural resources and the development of effective recycling technologies [5,6].

Although some synthetic fibre reinforcements can be directly replaced by alternative sustainable natural fibres, it has been shown that the greatest environmental footprint of composites when they replace metals is due to the use of petroleum-based matrix polymers, rather than the use of reinforcement fibres [7]. The growing interest to develop bio-based resins is, therefore, aligned with the solution of all these problems.

Meanwhile, since the use of composites with petroleum-based polymers cannot yet be replaced in many industrial applications, the solution is to maximize its utilization to reduce end-of-life disposal as plastic waste. Hodzic [4], for example, proposes the following solutions: (i) re-create virgin material for other applications using the extracted monomers; (ii) develop cost-effective recycling processes that justify their re-use; (iii) develop biodegradable and naturally sourced polymers; (iv) develop biochemical degradation processes to shorten polymeric chains.

Regarding recyclability and reutilization, the past few years have seen the development of several technologies capable of handling the problems posed by the recovery of the individual constituent materials from the typical heterogeneous hybrid structure of composites, as shown in Figure 1a. Mechanical processes, such as grinding, as shown in Figure 1b, are relatively cheap and allow for the recovery of the composites as small granulates or powder to be used as reinforcements for polymers or cement applications. Thermal pyrolysis, as shown in Figure 1c, which is more expensive, allows for the production of particles with smaller or longer sizes and shapes at the expense of some loss in mechanical behaviour. It is also possible to recover the fibres by burning the composite, but the resulting mechanical properties will be significantly lower. Chemical processes, as shown in Figure 1d, are also able to produce small and long particles $(300 \mu \mathrm{m}$ to $100 \mathrm{~mm})$ with lower losses in mechanical performance than pyrolysis [8-19].

Although the abovementioned technologies allow for the recovery of some material and are theoretically good for global sustainability, they still have a negative environmental impact due to the use of organic solvents, energy consumption for achieving the required temperatures and pressures and, due to the investments in equipment, R\&D and advertisement [20].

Under these circumstances, the development of bio-composites with at least one constituent derived from a natural source seems to be a viable answer to the actual impasse in terms of the environmental impact of composite production versus the impact of their recyclability. Green composites, which are totally made from natural fibres embedded in a plant-based matrix or other natural resin, assume special relevance in the solution of the abovementioned impasse [21-23].

Nowadays it is possible to find a variety of bio-composites produced from polymeric resins from renewable resources, such as vegetable oils [24], poly-L-lactic acid [6] and furan resins [25]. Within plant oils as feedstock for polymeric biomaterial, the utilization of soybean oil in the development of bio-based thermosetting matrices is gaining greater attention [26,27]. Particularly, acrylate epoxidase soybean oil (AESO), which is synthesized from soybean oil via epoxidation and acrylation, has attracted great research interest [27-29].

Several natural fibre reinforcements, such as jute, sisal, bamboo, kenaf and flax have been used to fabricate bio-composites for different applications. [30,31]. Natural fibres have several advantages over traditional reinforcing fibres, such as accessibility from renewable resources, biological degradation, 
non-abrasive processing, good adhesion, especially after treatment, and low density and cost. However, they often suffer from moisture absorption, low thermal and UV resistance and quality variations [26].

Research in the field of recovering natural fibre composites is a relatively unexplored topic when compared to the recyclability of synthetic fibre reinforced composites. For the latter, different strategies have been proposed, mainly due to the relatively high cost and energy consumption to produce synthetic fibres $[15-19,32,33]$. Although the number of studies in the recyclability of natural fibre reinforcement composites is scarce, some works show that their mechanical and physical properties remain practically unchanged and can even be enhanced, due to the new generated surfaces after the recycling process. This justifies the investment in their recovery and reutilization [34,35].

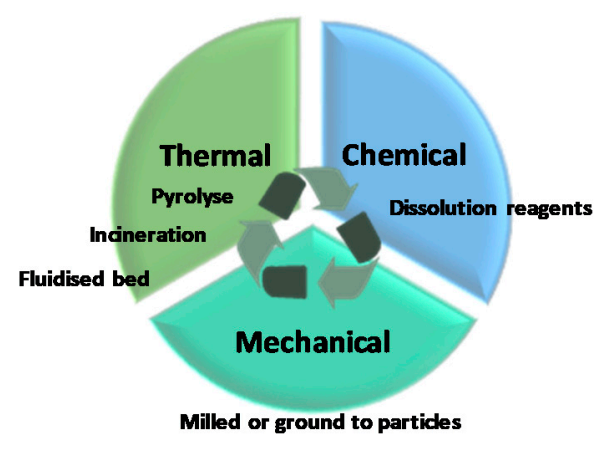

(a)

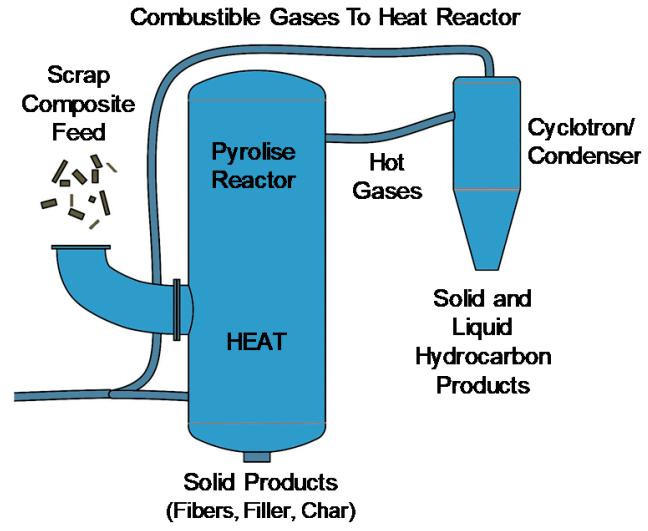

(c)

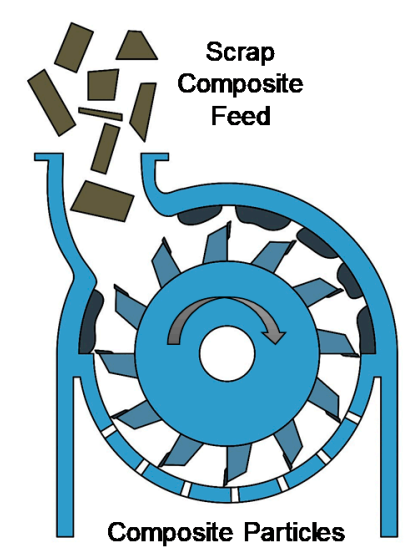

(b)

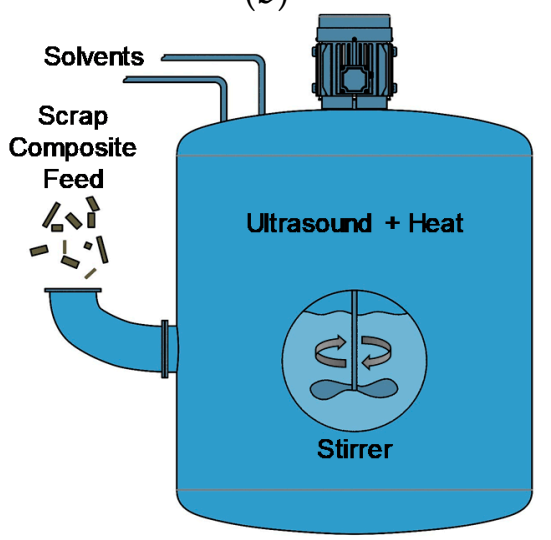

(d)

Figure 1. (a) Recycling methods; (b) Grinding-Mechanical process; (c) Pyrolise-Thermal process;

(d) Dissolution-Chemical Process.

Hence, by focusing on green polymers, research efforts should be directed to the characterization of the pros and cons of the different materials, as well as on their ability to provide good interface performance. It is authors' conviction that this is the pathway to the enhance sustainability of the composites industry and to cope with the new trends in recyclability and reuse in circular economy [36].

This paper is driven by this conviction and aims to produce a green composite from renewable materials (acrylate epoxidase soybean oil, as resin, and sisal and jute as reinforcement materials), and to investigate its chemical, physical and mechanical performances, as well as its recyclability and reuse as a second-life composite. The recovering of reinforcement and resin materials was performed at room temperature and atmospheric pressure and these resources were reused in the manufacturing of a second-life composite, whose properties were also investigated.

Jute fabric and sisal particles were chosen for the reinforcement and filler because they are natural materials with good mechanical properties. Besides their biodegradability and low price, they offer 
significant processing advantages, such as non-abrasive and high specific strength, due to their high lignocellulosic content $[7,23]$. Acrylated epoxidized soybean oil (AESO) was chosen as matrix because it is obtained from soybean vegetable oil, one of the most promising starting materials to produce thermosetting polymers, due to its high availability, low toxicity, sustainability and relatively low cost [27-29].

\section{Experimentation}

\subsection{Materials and Methods}

The work used a commercial acrylate epoxidase soybean oil (AESO), $\mathrm{d}=1.04 \mathrm{~g} / \mathrm{mL}$ at $25^{\circ} \mathrm{C}$ with inhibitor (4000 ppm monomethyl ether hydroquinone) as matrix material and tert-butyl peroxybenzoate (TBPB, $98 \%$ ) as hardener, both supplied by Sigma-Aldrich. Reinforcement fibres of sisal rope, crushed to small particles $( \pm 1 \mathrm{~mm})$, were used as filler. A dark brown biodegradable jute fabric produced by a binary system of simple interlacing-where a warp yarn is over or under a weft yarn at the crossover areas-was also used in the production of virgin and second-life composites. Both sisal rope and jute fabric were purchased from a local supplier and used with no further treatment in order to avoid increasing the overall manufacturing costs.

The resin specimens were prepared with different contents $(0,5$ and $10 \mathrm{wt} \%$ based on AESO) of sisal particles (SP) added to the viscous liquid AESO. The particles were mechanically stirred at $40^{\circ} \mathrm{C}$ for $5 \mathrm{~min}$, to ensure uniform dispersion and the resulting mixture was subsequently subjected to the addition of different contents $(2,5$ and $10 \mathrm{wt} \%)$ of hardener. After further stirring for $2 \mathrm{~min}$, full homogeneity was achieved and the resulting mixtures were poured into an aluminium test specimen mould. The mould was manufactured on the Cincinatti Arrow VMC-500 CNC milling machine (Cincinnati, OH, USA), according to ISO D638-03 testing standards, as shown in Figure 2a.

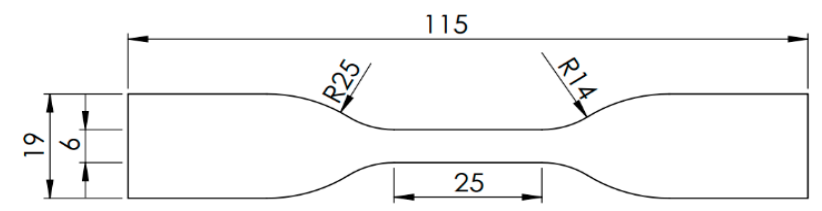

(a)

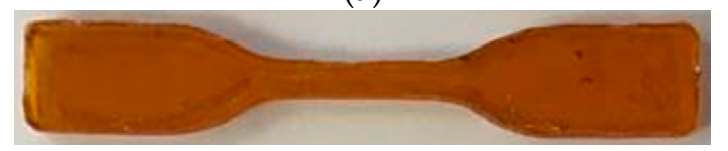

(b)

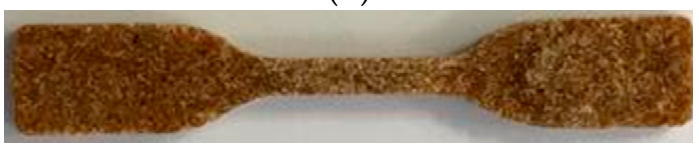

(c)

Figure 2. Tensile tests: (a) Specimen dimensions; (b) Resin specimen produced with AESO, $5 \mathrm{wt} \%$ hardener and $0 \%$ sisal particle, H5SP0; (c) Resin specimen produced with AESO, $5 \mathrm{wt} \%$ hardener and $10 \mathrm{wt} \%$ sisal particles, H5SP10.

The curing process was performed in an atmospheric pressure oven at $120{ }^{\circ} \mathrm{C}$ during $2 \mathrm{~h}$, followed by an additional $4 \mathrm{~h}$ stage at $160^{\circ} \mathrm{C}$. After being cooled to room temperature, the test samples were removed from the moulds.

The different resin combinations led to the production of nine different samples that were identified with the acronyms $\mathrm{HxSPx}$, where $\mathrm{H}$ and $\mathrm{SP}$ refer to hardener and filler and $\mathrm{x}$ represents the respective content $(w t \%)$. Figure $2 b, c$ show the final visual aspect of the test specimen produced with AESO and $5 \mathrm{wt} \%$ of hardener with $0 \mathrm{wt} \%$ (H5SP0) and $10 \mathrm{wt} \%$ (H5SP10) SP, respectively. 
Once the resin best performance conditions were determined $(5 \mathrm{wt} \%$ hardener and $0 \mathrm{wt} \%$ or $10 \mathrm{wt} \%$ sisal particles as filler), green composite testing samples were produced via a wet layup method with five layers of bi-directional jute fabric as reinforcement ( $5 \mathrm{~g}$ per layer) and $50 \mathrm{~g}$ and $40 \mathrm{~g}$ of AESO for virgin and second-life composites, respectively. The production process was similar to the one described above.

After recycle assessment, two second-life composites were produced using recycled jute fibres and a third was produced using $40 \%$ of the recovered resin and $60 \%$ AESO. The same nomenclature was followed, and the samples were identified as CoHxSPxFR, where Co and FR refer to composite and recycled jute fabric (or RR recycled resin), respectively.

Figure 3 summarizes the methodology and different characterization tests that support the objectives of the work. Once the resin best performance conditions were determined ( $5 \mathrm{wt} \%$ hardener and $10 \mathrm{wt} \%$ sisal particles as filler or without filler), green composite testing samples were produced, and all tests were performed at least in triplicate.
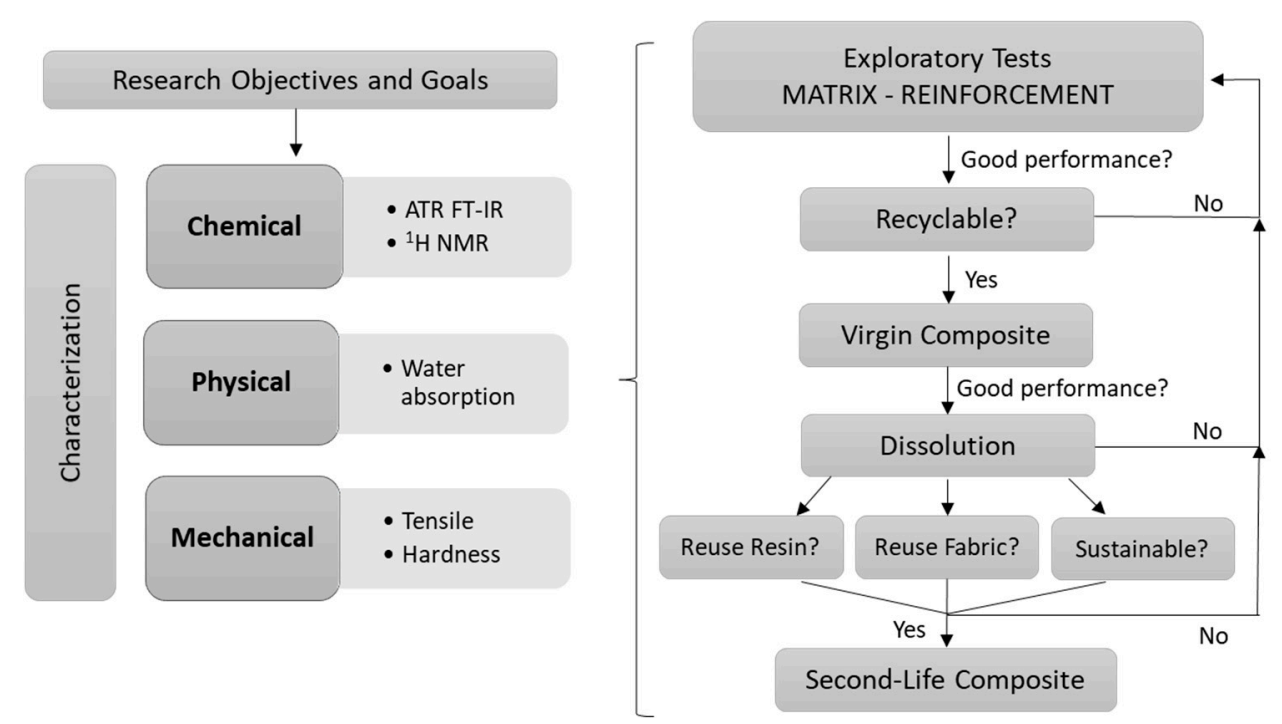

Figure 3. Schematic diagram of research methodology for manufacturing a recyclable green composite.

\subsection{Testing Procedures}

\subsubsection{Chemical Characterization}

Chemical characterization was performed by attenuated total reflectance Fourier transform infrared (ATR FT-IR) spectroscopy whose spectra were recorded in IRAffinity-1S Shimadzu apparatus (Kyoto, Japan), equipped with an ATR ZnSe Performance Crystal Plate accessory (4000-400 $\mathrm{cm}^{-1}$ range with $2.0 \mathrm{~cm}^{-1}$ resolution). Proton nuclear magnetic resonance $\left({ }^{1} \mathrm{H}\right.$ NMR) spectrometry was performed on a Bruker AdvanceII+ Spectrometer $\left(300 \mathrm{MHz}\right.$ ) with $5 \mathrm{~mm}$ probe (Rheinstetten, Germany), in $\mathrm{CD}_{2} \mathrm{Cl}_{2}$ as solvent.

\subsubsection{Physical Characterization}

Physical characterization consisted of water absorption tests that were carried out with samples $(\sim 19 \times 24 \times 2 \mathrm{~mm})$ that were dried at $55^{\circ} \mathrm{C}$ for $24 \mathrm{~h}$ to remove residual moisture that diffuse along the interfaces. Higher temperatures $\left(>66^{\circ} \mathrm{C}\right)$ were not used because they can affect the structure of the samples and promote microcracking [37]. Dry samples were weighed in a semi-analytical balance $( \pm 0.001 \mathrm{~g})$ and immersed in containers with $40 \mathrm{~mL}$ of pure water. After $24 \mathrm{~h}$, at room temperature, 
the samples were removed, softly wiped with absorbent paper and weighed again. The water uptake rate $(\%)$ was calculated according to the following expression:

$$
\operatorname{Wup}(\%)=\frac{W_{f}-W_{i}}{W_{i}} \times 100
$$

where $W_{i}$ and $W_{f}$ are the initial and final weights of the samples, respectively.

\subsubsection{Mechanical Characterization}

Tensile and hardness tests were performed to characterize the mechanical properties of the composites. The tensile tests were carried out in a Shimadzu (Kyoto, Japan) AG IS $20 \mathrm{kN}$ testing machine equipped with a $10 \mathrm{kN}$ load cell and the hardness tests were done in a Zwick (Ulm, Germany) durometer that allowed measurements on the Shore A scale.

\subsection{Recyclability}

The recycling process was performed in rectangular cured AESO resin samples $(\sim 19 \times 24 \times 2 \mathrm{~mm})$ using seven organic solvents, namely ethanol, 1-buthanol, acetone, methyl acetate, ethyl acetate, dichloromethane and chloroform. Samples were immersed in containers with $20 \mathrm{~mL}$ pure solvents with mechanical stirring at room temperature and dissolution and matrix breakdown were monitored over time $(24 \mathrm{~h})$. The same procedure was performed with selected solvents with composite samples.

\section{Results and Discussion}

\subsection{Chemical Characterization}

Sisal fibre, one of the most widely used natural fibres, is fully biodegradable and $65 \%$ of its composition is cellulose, with the remaining $35 \%$ composed of hemicellulose, lignin and waxes [38]. Cellulose is a polysaccharide consisting of a linear chain of over $500 \beta-1,4$ linked d-glucose units, as presented in Figure 4. AESO is produced by the epoxidation of fatty acid double bonds followed by epoxy ring acrylation and its chemical structure is composed of fatty acid long aliphatic chains with various functional groups, such as the acrylate, epoxy and hydroxy, as schematized in Figure 4.

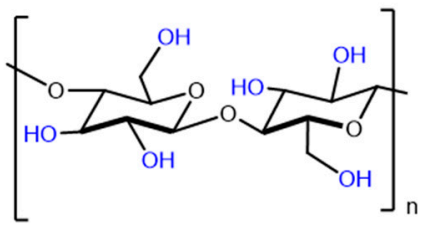

Cellulose

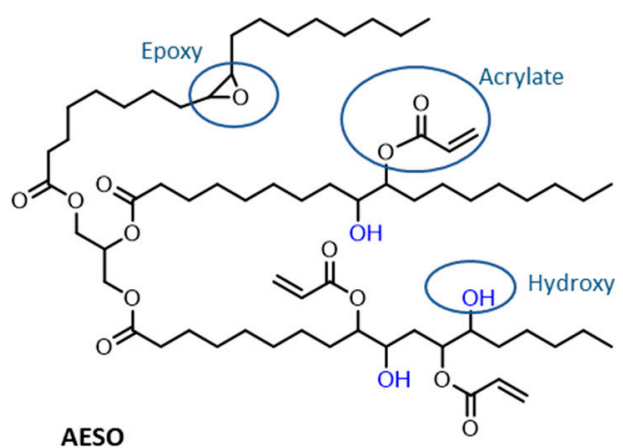

AESO

Figure 4. The chemical structure of cellulose and acrylate epoxidized soybean oil.

Chemical structures were confirmed by the ATR FT-IR spectra, which were recorded for initial materials (AESO and SP) and the nine exploratory samples produced (data not shown). This technique allowed us to identify the chemical functional groups and investigate the possible interactions and chemical bonding established between the AESO resin and SP fibres. Since the results were very similar for all the cured samples, a representative example is presented for the cured samples H5SP0 and H5SP10. Figure 5 shows the comparative analysis of the ATR FT-IR spectra of pure sisal particles, pure AESO and cured samples manufactured with $5 \mathrm{wt} \%$ hardener, H5SP0 (without SP) and H5SP10 (with $10 \mathrm{wt} \% \mathrm{SP}$ ), respectively. 


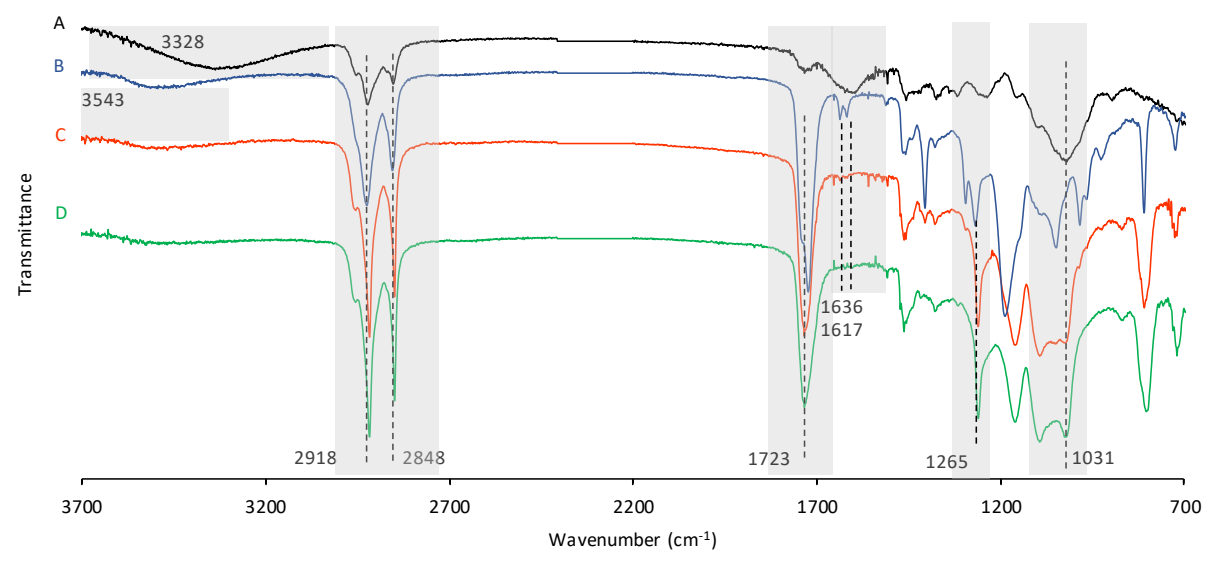

Figure 5. ATR FT-IR spectra of: (A) Sisal particles; (B) AESO; (C) Cured AESO manufactured with 5\% hardener (H5SP0); (D) Cured AESO manufactured with 5\% hardener and 10\% SP (H5SP10).

In the spectrum of SP, as shown in Figure 5A the lignocellulosic matrix is recognised by the presence of a broad band at $3328 \mathrm{~cm}^{-1}$, characteristic of the stretching vibration of hydroxyl $(-\mathrm{OH})$ groups and by the characteristic signals at, $2921 \mathrm{~cm}^{-1}, 2850 \mathrm{~cm}^{-1}$ and $1018 \mathrm{~cm}^{-1}$ assigned to the stretching vibrations of $\mathrm{C}-\mathrm{H}$ and $\mathrm{C}-\mathrm{O}-\mathrm{C}$, respectively. In the pure AESO spectrum, as shown in Figure $5 \mathrm{~B}$, the $-\mathrm{OH}$ stretch was shifted to $3543 \mathrm{~cm}^{-1}$ and the characteristic ester $(\mathrm{C}=\mathrm{O})$ and $(\mathrm{C}-\mathrm{O})$ stretching bands were observed at $1723 \mathrm{~cm}^{-1}$ and $1265 \mathrm{~cm}^{-1}$, respectively. The characteristic $\mathrm{C}-\mathrm{H}$ stretching bands of the $\mathrm{CH}_{2}$ and $\mathrm{CH}_{3}$ groups of saturated chains were observed at 2918 and $2848 \mathrm{~cm}^{-1}$ and the $\mathrm{C}-\mathrm{H}$ bending band was identified at $1458 \mathrm{~cm}^{-1}$. Moreover, the bands at $1186 \mathrm{~cm}^{-1}$ and $1046 \mathrm{~cm}^{-1}$ can be identified due to the $\mathrm{C}-\mathrm{O}-\mathrm{C}$ stretching vibration of ester and also at $809 \mathrm{~cm}^{-1}$ in the epoxy band. The two weak bands at 1636 and $1617 \mathrm{~cm}^{-1}$, characteristic of the $\mathrm{C}=\mathrm{C}$ stretch, disappear, as expected, after the curing process, as shown in Figure 5C,D. Comparative analysis between the spectra of cured AESO and H5SP10 allows us to conclude that they follow the same trend, with a slight change in the peak at $1031 \mathrm{~cm}^{-1}$ due to the cumulative effect of the sisal particles. This similarity shows that the added SP has no covalent bonds with AESO, as also reported by Liu et al. [28] with microcrystalline cellulose.

AESO structural characterization after the curing and recycling processes were performed by ${ }^{1} \mathrm{H}-\mathrm{NMR}$. Spectra of origin AESO, cured AESO and AESO recovery from the dissolution process, obtained in $\mathrm{CD}_{2} \mathrm{Cl}_{2}$, are presented in Figure 6.

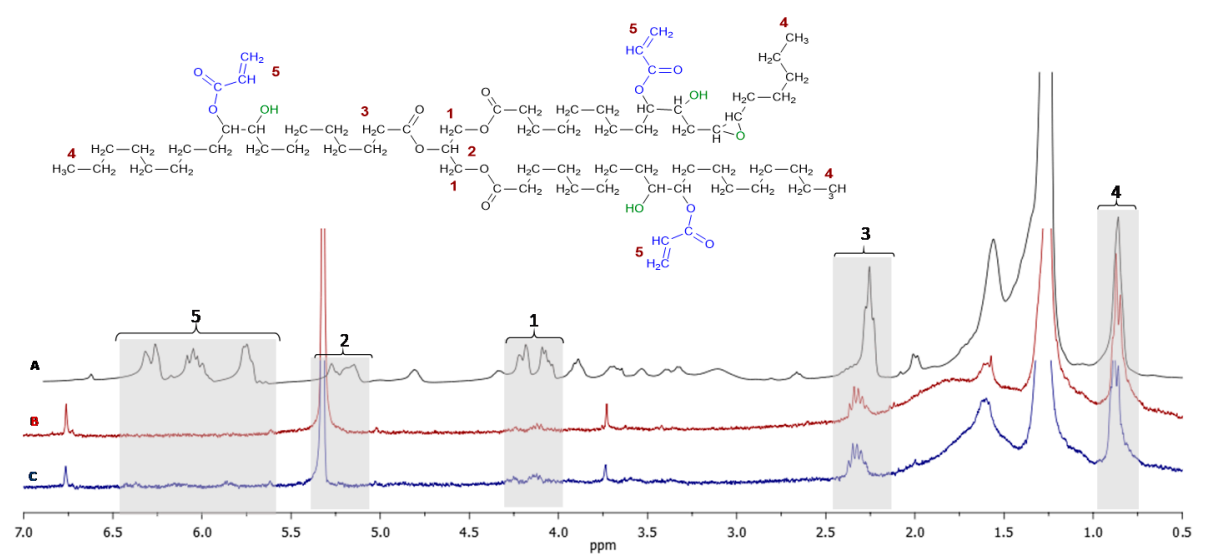

Figure 6. ${ }^{1} \mathrm{H}-\mathrm{RMN}$ in $\mathrm{CD}_{2} \mathrm{Cl}_{2}$ of: (A) AESO, (B) Cured AESO, (C) AESO recovery from the dissolution process.

For pure AESO, as shown in Figure 6A, the spectrum analysis allows us to identify the signals for the different protons in the expected areas. In the region between 0.75 and $1.00 \mathrm{ppm}(4)$, the signal 
corresponding to the terminal $\mathrm{CH}_{3}$ groups of the chains is identified and the $\mathrm{CH}_{2}$ groups, in $\alpha$ position relative to the carbonyl group $(\mathrm{C}=\mathrm{O})$, are identified by the presence of the triplet at $2.3 \mathrm{ppm}(3)$. The three signals in the range between 5.75 and $6.50 \mathrm{ppm}$ are attributed to the presence of the acrylate groups (5) and the central protons of the structure (1 and 2) are attributed to the signals between 4.10 and $4.50 \mathrm{ppm}$ and 5, 2.5 and $5.50 \mathrm{ppm}$, respectively. The spectra of cured AESO, as shown in Figure $6 \mathrm{~B}$, and recovery AESO from the recycling process, as shown in Figure $6 \mathrm{C}$, present the same trend, showing that no structural changes occurred during the recycling process. The absence of the signals of acrylate groups (5) in both cured AESO samples, as shown in Figure 6B,C, confirms the ATR FT-IR results.

\subsection{Physical Characterization}

Water absorption rates for the specimens produced with AESO resin and different hardener $(2,5$ and $10 \mathrm{wt} \%)$ and SP $(0,5$ and $10 \mathrm{wt} \%)$ contents were evaluated after $24 \mathrm{~h}$ submersion in water, as shown in Figure 7. The results followed a common trend with the incorporation of SP producing an increase in the amount of water uptake, reaching values between $2.0-2.7 \mathrm{wt} \%$ and $3.9-4.8 \mathrm{wt} \%$ for 5 and $10 \mathrm{wt} \% \mathrm{SP}$, respectively.

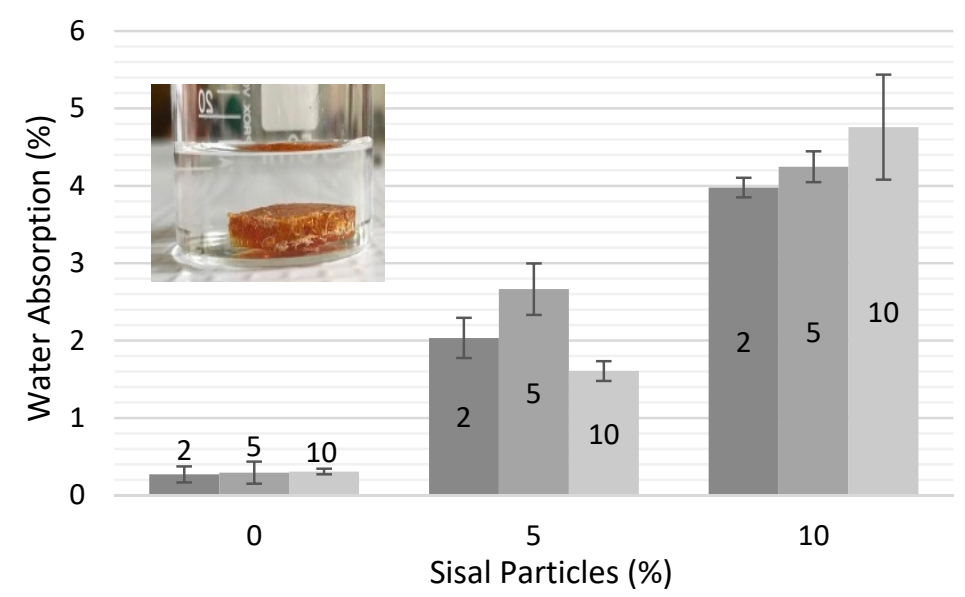

Figure 7. Effect of sisal fibre and hardener (refer to the percentage of hardener inside each column) on water absorption rate.

These results cope with the predictable behaviour of the green composite, due to the hydrophilic nature of the cellulosic filler, which contains a large number of hydroxyl $(\mathrm{OH})$ groups that highly interact with water molecules. For the unfilled AESO samples ( $0 \% \mathrm{SP})$, the amount of hardener does not significantly influence the water uptake percentages with values of $0.27,0.29$ and $0.31 \%$, for 2,5 and $10 \mathrm{wt} \%$ hardener, respectively. In accordance with the report by Liu et al. [28], AESO contains, in their molecular chain structure, polar hydroxy and epoxy groups which, due to its hydrophilicity, are responsible for the inherent water absorption rate of unreinforced samples.

The out-of-trend results obtained for $10 \mathrm{wt} \%$ hardener are attributed to the curing process that influences the overall homogeneity of the specimens-namely the dispersion of the sisal particles (heavier sisal particles are deposited on the bottom of the mould). Resin contraction variations may also induce small voids and cracks in the specimens that will act as water collectors.

\subsection{Mechanical Characterization}

Figure 8 shows the results obtained for the hardness and tensile tests performed on nine AESO resin specimens manufactured with 2, 5 and $10 \mathrm{wt} \%$ hardener and 0,5 and $10 \mathrm{wt} \%$ sisal particles. 


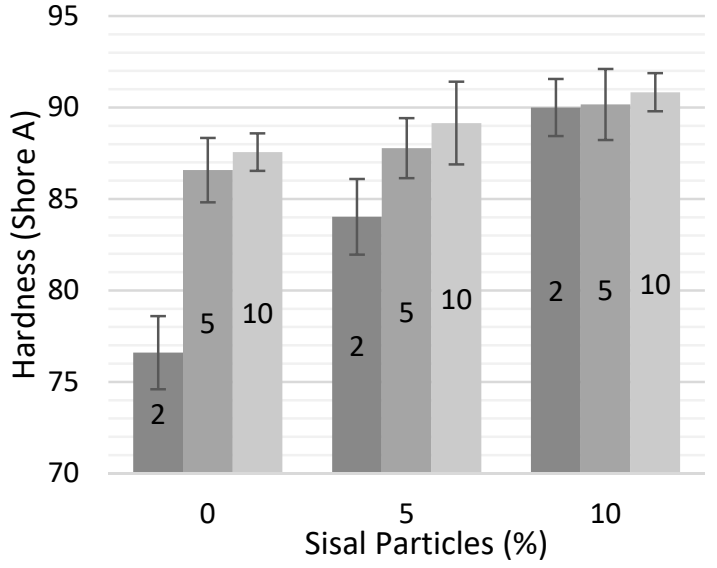

(a)

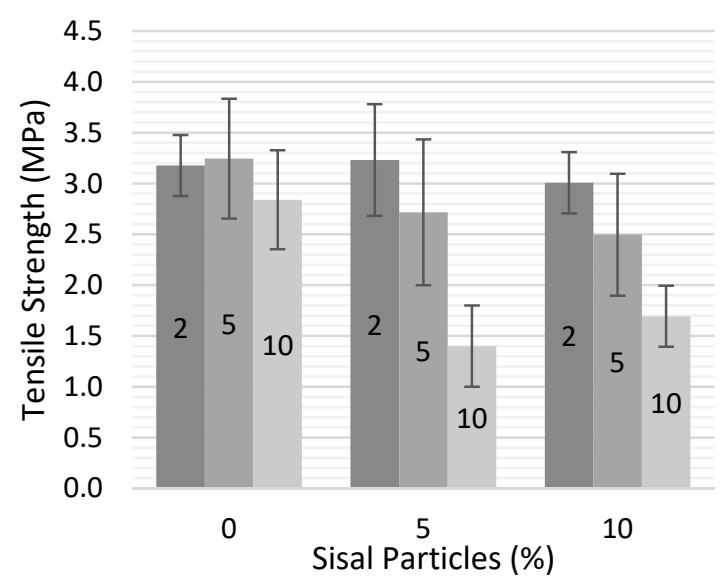

(b)

Figure 8. Mechanical tests of resin specimens with different sisal particles and hardener percentages (refer to the percentages of hardener inside each column): (a) Hardness; (b) Tensile strength.

Figure 8a shows that the addition of the sisal particles or hardener enhances material hardness. In the case of specimens with lower hardener percentage, for example $2 \mathrm{wt} \%$, sisal particles increase resin hardness, obtaining variations up to $14 \mathrm{HA}$. For specimens with higher hardener percentages, the fibre particles have a smaller influence, with gains below $5 \mathrm{HA}$. Although the hardness values of the samples (53.7-68.2 HA) were, in general, significantly higher than those found by Liu et al. [28], the tensile strength values presented in Figure $8 \mathrm{~b}$ are smaller than those found by other authors [28,29]. However, the overall trends are similar because Liu et al. [29] concluded that the hardening agent could also significantly increase the flexure strength value.

According to Figure $8 \mathrm{~b}$, higher sisal particles and hardener contents lead to a reduction in the tensile strength that the specimens are capable of withstanding. The specimen with $5 \mathrm{wt} \%$ hardener and no fibre, H5SP0, has the best performance, supporting a tensile strength of $3.25 \mathrm{MPa}$. In fact, contrary to hardness, the addition of sisal particles causes a reduction in strength. The small exception observed for the leftmost results of Figure $8 \mathrm{~b}$ are, once again, attributed to the curing process, because some specimens became slightly concave after being removed from the oven.

From tensile tests it was also possible to conclude that the highest content of sisal particles showed the lowest fracture strength. Ductility was generally poor, varying from $2 \%$ (H10SP5) up to $11 \%$ for H5SP0, and the elasticity modulus ranged from approximately $50 \mathrm{MPa}$ (H10SP10) to $120 \mathrm{MPa}$ for H5SP5.

After concluding the physical, chemical and mechanical tests, the compositions with $5 \mathrm{wt} \%$ hardener $+0 \%$ sisal particles, $\mathrm{H} 5 \mathrm{SP} 0$, and $5 \mathrm{wt} \%$ hardener $+10 \mathrm{wt} \%$ sisal particles, H5SP 10 , were selected for the preparation of the virgin composites as well as for the investigation into recyclability and second-life production and performance. Specimens with $5 \mathrm{wt} \%$ fibre particles and $2 \mathrm{or} 5 \mathrm{wt} \%$ hardener were excluded, despite presenting good results because, after curing, they gave rise to the deposit of fibres at the bottom of the mould and to some variation in the experimental results.

\subsection{Recyclability}

Since one of the objectives of the present work is the implementation of a recycling protocol, which allows for the production of second-life composites, the preliminary test dissolution behaviour of cured AESO resins were performed with solvents from different chemical categories: alcohol; ketone; ester; halogenated.

From all the organic solvents tested, those that belong to the halogenated family proved to be the most effective to dissolve the AESO resin matrix both before and after the curing process, followed by 
acetone. Alcohols and esters proved to dissolve the AESO resin before the curing process but, after curing, its dissolution was very slow (alcohols) or did not even occur (esters). Regarding the virgin composites, dichloromethane was able to separate the entire five layers of jute and recover the AESO resin particles after $30 \mathrm{~min}$, while acetone achieved a similar result after $2 \mathrm{~h} 30 \mathrm{~min}$. The results are shown in Figure 9.
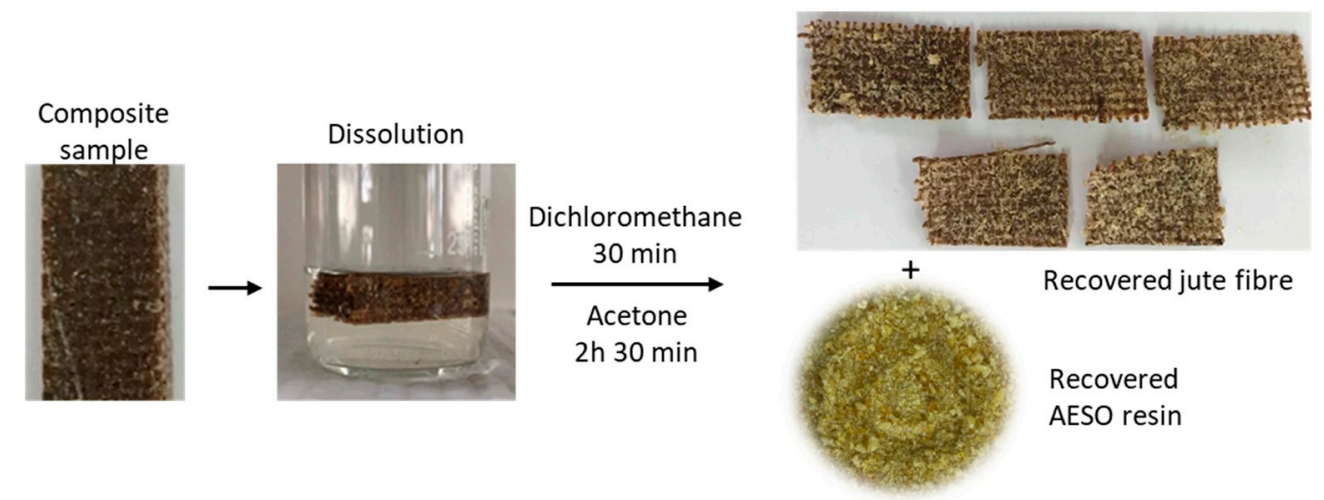

Figure 9. Dissolution process of virgin composite in dichloromethane or acetone. Separation of recovery jute samples and AESO polymer.

However, despite the higher dissolution rate of dichloromethane over acetone, the latter was selected due to its better performance according the safety, health and environmental (SHE) criteria, as shown in Table 1.

Table 1. CHEM21 solvent guide of "classical" solvents. Adapted from [39].

\begin{tabular}{lccccccc}
\hline \multicolumn{1}{c}{ Family } & Solvent & $\mathbf{B P}\left({ }^{\circ} \mathbf{C}\right)$ & FP $\left({ }^{\circ} \mathbf{C}\right)$ & Safety Score & Health Score & Env. Score & $\begin{array}{c}\text { Ranking after } \\
\text { Discussion }\end{array}$ \\
\hline Alcohol & Ethanol & 78 & 13 & 4 & 3 & 3 & Recommended \\
\multirow{5}{*}{ Ketones } & 1-Butanol & 118 & 29 & 3 & 4 & 3 & Recommended \\
Ester & Acetone & 56 & -18 & 5 & 3 & 5 & Recommended \\
\multirow{5}{*}{ Halogenated } & Methyl Acetate & 57 & -10 & 5 & 3 & 5 & Problematic \\
& Ethyl Acetate & 77 & -4 & 5 & 3 & 3 & Recommended \\
& Dichloromethane & 40 & - & 1 & 7 & 7 & Hazardous \\
& Chloroform & 61 & - & 2 & 7 & 5 & Highly hazardous \\
\hline
\end{tabular}

BP: boiling point, FP: flash point. Higher numbers correspond to higher hazard or toxicity for safety, health and environmental hazards.

After the dissolution process, the structural integrity of the recycled/recovered AESO resin was accessed by proton NMR, as shown in see Figure 6C, and compared with the original sample, showing that no structural changes occurred during the recycling process. The recycled resin particles, as well as the recovered jute fabric, were used to produce second-life composites and their performances were evaluated together with the previous virgin composites.

\subsection{Virgin and Second-Life Composites}

Virgin and second-life composites were produced and their performance evaluated after selecting the resins and establishing the chemical recycling procedure.

\subsubsection{Physical Characterization}

Water absorption was analysed for both virgin (CoH5SP0 and CoH5SP10) and second-life composites (CoH5SP0FR, CoH5SP10FR and CoH5SP10RR). Compared to the respective resin samples, which provided a maximum absorption of $4.2 \mathrm{wt} \%$ for the H5SP10 sample, as shown in Figure 7 in the first part of the paper, the incorporation of the jute reinforcement in the new virgin and second-life composites resulted in a significant increase in water absorption, reaching values of $11.3 \%$ in the 
case of CoH5SP10, as shown in Figure 10. The high hydrophilicity characteristics of the jute fabric, which allows for absorbing almost $110 \%$ of its weight and may even induce more voids to entrap more water, is responsible for these results.

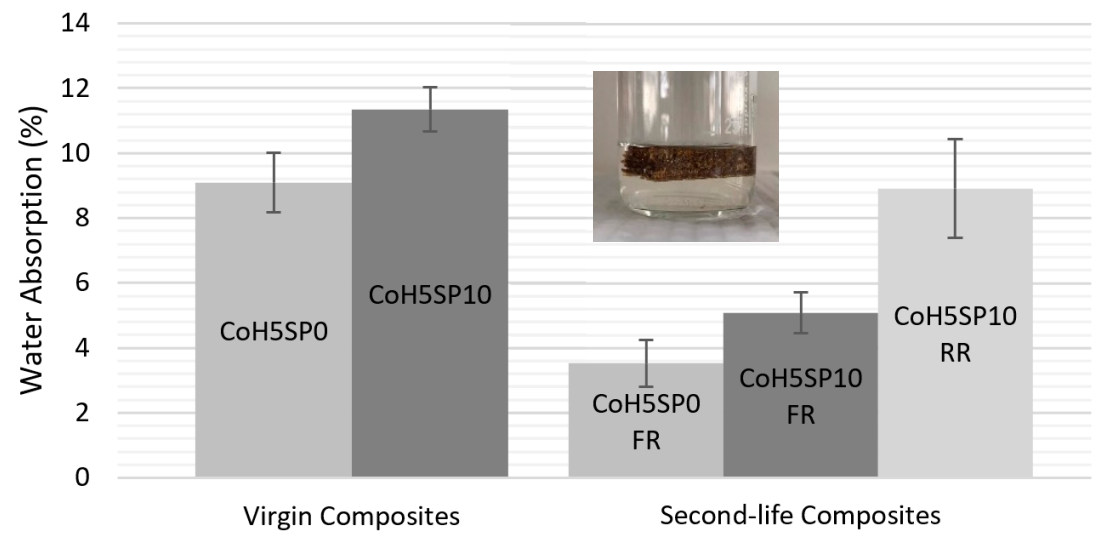

Figure 10. Water absorption tests for virgin and second-life composites.

The corresponding second-life composites produced with the recovered jute fabric (CoH5SP0FR and $\mathrm{CoH} 5 \mathrm{SP} 10 \mathrm{FR}$ ) presented lower water absorption (less 56-62\%) than the virgin composites (CoH5SP0 and $\mathrm{CoH} 5 \mathrm{SP} 10$ ) but the overall evolution trend is similar because water absorption resistance diminishes with the addition of sisal particles. A possible explanation for the enhanced water absorption resistance of the second-life composites may be related with the saturation of the jute fabric exposed to the recycling process, and to a better uniform adhesion of the new matrix.

The second-life composite, CoH5SP10RR, produced with recovered resin particles, absorbs less than $22 \%$ of the water than the original virgin composites, but approximately $80 \%$ more water than the other second-life composites.

The abovementioned results show that the production of second-life composites helps in the reduction in water absorption, which is commonly pointed out as a negative feature of green composites. They also allow for the conclusion that the variation in the properties of the recycled resin will have less impact on water absorption when compared to second-life composites manufactured without recycled resin.

\subsubsection{Mechanical Characterization}

Figure 11 shows the hardness and tensile strengths of virgin and second-life composites fabricated with $5 \mathrm{wt} \%$ hardener, and $0 \%$ or $10 \mathrm{wt} \%$ sisal particles. A first comparison of the hardness measurements obtained with virgin composites $\mathrm{CoH} 5 \mathrm{SP} 0 / 10$, as shown in Figure 11a, and resin test specimens H5SP0/10, as shown in Figure 8a, allows for the conclusion that the results are similar with a positive influence of sisal particles on the final hardness of the composites.

A similar comparison for the tensile strength values, as shown in Figure 11b, provides different conclusions. Firstly, the overall levels of tensile strength are significantly higher for the composites because the resin test specimens were produced without jute fabric. Secondly, the combined presence of jute fabric and sisal particles improves the tensile strength of the composites. This last conclusion is opposite to that obtained from the resin test specimens, probably because the heterogeneity caused by the presence of sisal particles dispersed in the resin matrix is only mechanically effective in the presence of jute fabric.

Second-life composites are more difficult to analyse because the results obtained with CoH5SP10FR seem to be out-of-trend against those obtained with CoH5SP0FR and against what was said above. A possible explanation for the out-of-trend results of CoH5SP10FR and for presenting a tensile strength $50 \%$ lower than that of the virgin composite CoH5SP10 may be related to the non-uniform distribution of sisal particles. In fact, the recycling of the jute fabric always keeps some resin residues that constrain 
sisal particles to penetrate the core of the specimens, thereby increasing its concentration at the surface. Hence, hardness increases slightly more than expected and tensile strength decreases to values close to the resin test specimens, because cracks are triggered at the centre of the specimens during tensile tests.

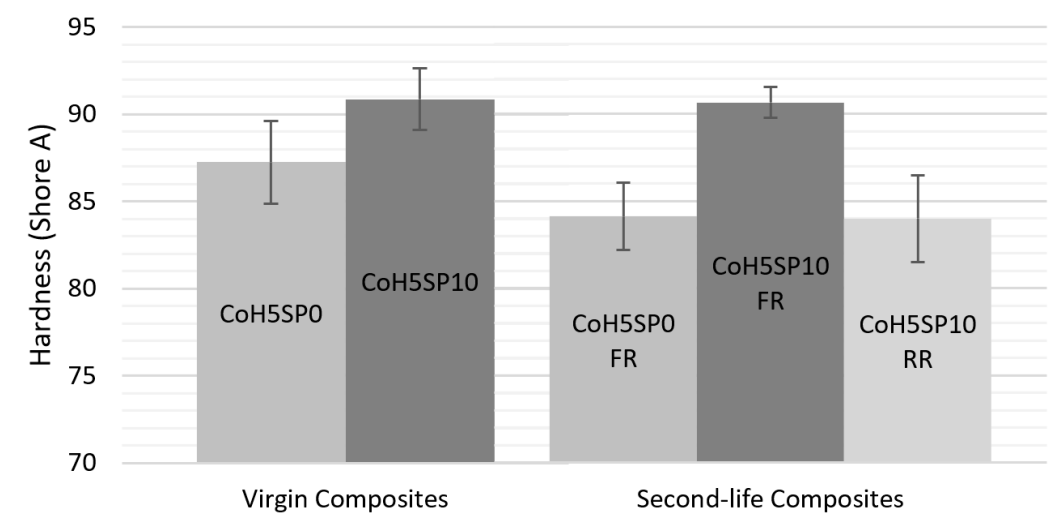

(a)

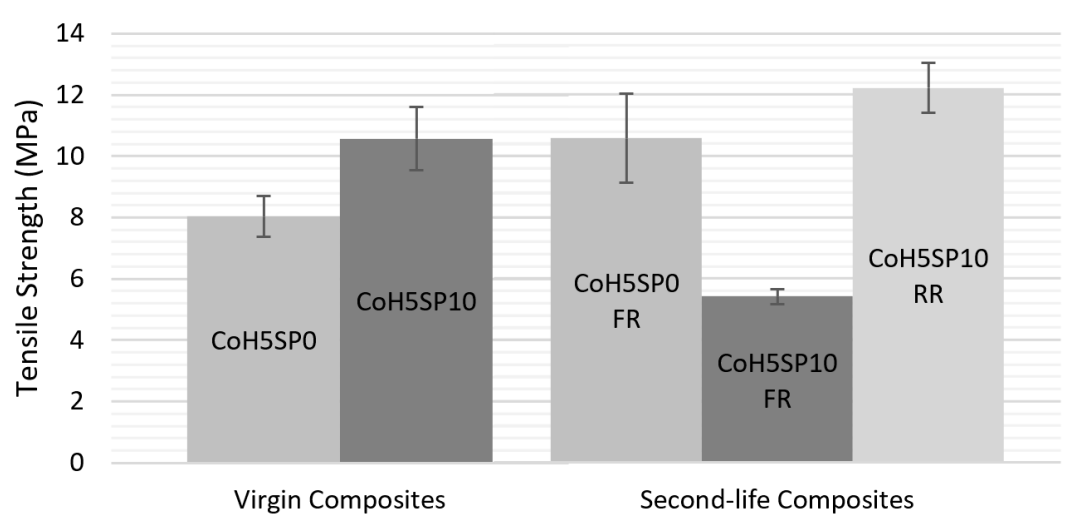

(b)

Figure 11. Mechanical tests for virgin and second-life composites: (a) Hardness; (b) Tensile strength.

Regarding the composite manufactured with reused resin (COE5F10RR), it presents the highest mechanical strength, probably because the reused resin already contains small sisal particles from previous utilization, which enables for the attainment of a composite with a uniform distribution of sisal particles throughout the thickness of the specimens.

\section{Conclusions}

This work allowed for the conclusion that is possible to manufacture green composite with renewable materials and that it is also possible to reuse the materials for a second-life composite. The experiments made use of jute fabric as reinforcement, acrylate epoxidase soybean oil (AESO) as matrix and sisal particles (SP) as filler. The recycling process was performed with acetone, an organic solvent recommend by the SHE criteria. The best mechanical performance (hardness of 91 Shore A and tensile strength of $10.6 \mathrm{MPa}$ ) of the virgin green composites was obtained with $10 \mathrm{wt} \%$ sisal particles and $5 \mathrm{wt} \%$ hardener. The second-life composites generally present a slight decrease in mechanical properties but have a higher resistance to water absorption, which is often considered the main problem associated with the use of green composites.

Author Contributions: Conceptualization I.M.F.B., C.P.S. and A.C.S.; investigation I.M.F.B., C.P.S., A.C.S., C.M.A.S. and M.A.R.L.; writing-original draft preparation I.M.F.B., C.P.S., A.C.S. and C.M.A.S.; writing-review and editing, M.A.R.L., M.P.R. and P.A.F.M. All authors have read and agreed to the published version of the manuscript. 
Funding: This research was developed with the financial support of Portuguese Fundação para a Ciência e Tecnologia, IDMEC under LAETA-UID/EMS/50022/2020 and CQE/IST-UIDB/00100/2020. The authors gratefully acknowledge the IST-UL NMR Network for facilities.

Conflicts of Interest: The authors declare no conflict of interest. The funders had no role in the design of the study; in the collection, analyses or interpretation of data; in the writing of the manuscript or in the decision to publish the results.

\section{References}

1. Bailleul, J.; Gillet, A.; Mantaux, O. Recovery and reuse of discontinuous carbon fibres by solvolysis: Realignment and properties of remanufactured materials. Compos. Sci. Technol. J. 2017, 139, 99-108.

2. Hughes, M. Applications. In Green Composites: Polymer Composites and the Environment; Baillie, C., Ed.; Woodhead: Cambridge, UK, 2004; pp. 233-251.

3. Fleischer, J.; Teti, R.; Lanza, G.; Mativenga, P.; Möhring, H.; Caggiano, A. Composite materials parts manufacturing. CIRP Ann. 2018, 67, 603-626. [CrossRef]

4. Hodzic, A. Re-use, recycling and degradation of composites. In Green Composites: Polymer Composites and the Environment; Baillie, C., Ed.; Woodhead: Cambridge, UK, 2004; pp. 252-271.

5. Oliveux, G.; Dandy, L.O.; Leeke, G.A. Current status of recycling of fibre reinforced polymers: Review of technologies, reuse and resulting properties. Prog. Mater. Sci. 2015, 72, 61-99. [CrossRef]

6. Tchana Toffe, G.; Oluwarotimi Ismail, S.; Montalvão, D.; Knight, J.; Ren, G. A Scale-up of Energy-Cycle Analysis on Processing Non-Woven Flax/PLA Tape and Triaxial Glass Fibre Fabric for Composites. J. Manuf. Mater. Process. 2019, 3, 92. [CrossRef]

7. Abdulla, L.C. Natural Fibers: The New Fashion of Modern Plastics Products. In INTROPica; Institute of Tropical Forestry and Forest Products: Serdang, Malaysia, 2008; Volume 2, pp. 6-7.

8. Karuppannan Gopalraj, S.; Kärki, T. A review on the recycling of waste carbon fibre/glass fibre-reinforced composites: Fibre recovery, properties and life-cycle analysis. SN Appl. Sci. 2020, 2, 433. [CrossRef]

9. Perry, N.; Mantaux, O.; Leray, D.; Lorriot, T. Composite recycling: Design for environment approach requirements. In Proceedings of the IDMME-Virtual Concept 2010, Bordeaux, France, 20-22 October 2010; GEDI P69.

10. Rybicka, J.; Tiwari, A.; Leeke, G.A. Technology readiness level assessment of composites recycling technologies. J. Clean. Prod. 2016, 112, 1001-1012. [CrossRef]

11. Howarth, J.; Mareddy, S.S.R.; Mativenga, P.T. Energy intensity and environmental analysis of mechanical recycling of carbon fibre composite. J. Clean. Prod. 2014, 81, 46-50. [CrossRef]

12. Naqvi, S.R.; Prabhakara, H.M.; Bramer, E.A.; Dierkes, W.; Akkerman, R.; Brem, G. A critical review on recycling of end-of-life carbon fibre/glass fibre reinforced composites waste using pyrolysis towards a circular economy. Resour. Conserv. Recycl. 2018, 136, 118-129. [CrossRef]

13. Dandy, L.O.; Leeke, G.A. Degradation of a model epoxy resin by solvolysis routes. Polym. Degrad. Stab. J. 2015, 118, 96-103.

14. Perry, N.; Bernard, A.; Laroche, F.; Pompidou, S. Improving design for recycling-Application to composites. CIRP Ann. 2012, 61, 151-154. [CrossRef]

15. Perry, N.; Pompidou, S.; Mantaux, O.; Gillet, A. Composite Fiber Recovery: Integration into a Design for Recycling Approach. In Technology and Manufacturing Process Selection; Springer: London, UK, 2014; pp. 281-296.

16. Pompidou, S.; Princaud, M.; Perry, N.; Leray, D. Recycling of Carbon Fiber: Identification of Bases for a Synergy between Recyclers and Designers. In Proceedings of the ASME 2012 11th Biennial Conference on Engineering Systems Design and Analysis, American Society of Mechanical Engineers Digital Collection, Nantes, France, 2-4 July 2012; pp. 551-560.

17. Li, J.; Xu, P.L.; Zhu, Y.K.; Ding, J.P.; Xue, L.X.; Wang, Y.Z. A promising strategy for chemical recycling of carbon fiber/thermoset composites: Self-accelerating decomposition in a mild oxidative system. Green Chem. 2012, 14, 3260-3263. [CrossRef]

18. Wang, Y.; Cui, X.; Ge, H.; Yang, Y.; Wang, Y.; Zhang, C.; Li, J.; Deng, T.; Qin, Z.; Hou, X. Chemical recycling of carbon fiber reinforced epoxy resin composites via selective cleavage of carbon -nitrogen bound. ACS Sustain. Chem. Eng. 2015, 3, 3332-3337. [CrossRef] 
19. Liu, Y.; Farnsworth, M.; Tiwari, A. A review of optimisation techniques used in the composite recycling area: State-of-the-art and steps towards a research agenda. J. Clean. Prod. 2017, 140, 1775-1781. [CrossRef]

20. Daniel, C.O. Assessing the role of green marketing in small and medium enterprises. Int. J. Sci. Res. Publ. 2019, 9, 693-699. [CrossRef]

21. Mitra, B.C. Environment Friendly composite materials: Biocomposites and Green composites. Def. Sci. J. 2014, 64, 244-261. [CrossRef]

22. Sharath Shekar, H.S.; Ramachandra, M. Green Composites: A Review. Mater. Today Proc. 2018, 5, $2518-2526$. [CrossRef]

23. Peças, P.; Carvalho, H.; Salman, H.; Leite, M. Natural fibre composites and their applications: A review. J. Compos. Sci. 2018, 2, 66. [CrossRef]

24. Zhang, C.; Garrison, T.F.; Madbouly, S.A.; Kessler, M.R. Recent advances in vegetable oil-based polymers and their composites. Prog. Polym. Sci. 2017, 71, 91-143. [CrossRef]

25. Mofidi, A.; Abila, J.; Ng, J.T.M. Novel Advanced Composite Bamboo Structural Members with Bio-Based and Synthetic Matrices for Sustainable Construction. Sustainability 2020, 12, 2485. [CrossRef]

26. Plackett, D.; Vázquez, A. Natural polymer sources. Green Composites-Polymer Composites and the Environment. In Green Composites: Polymer Composites and the Environment; Baillie, C., Ed.; Woodhead: Cambridge, UK, 2004; pp. 123-153.

27. Liu, W.; Fei, M.-E.; Ban, Y.; Jia, A.; Qiu, R.; Qiu, J. Concurrent improvements in crosslinking degree and interfacial adhesion of hemp fibers reinforced acrylated epoxidized soybean oil composites. Compos. Sci. Technol. 2018, 160, 60-68. [CrossRef]

28. Liu, W.; Fei, M.-E.; Ban, Y.; Jia, A.; Qiu, R. Preparation and Evaluation of Green Composites from Microcrystalline Cellulose and a Soybean-Oil Derivative. Polymers 2017, 9, 541. [CrossRef] [PubMed]

29. Liu, Z.S.; Erhan, S.Z.; Akin, D.E.; Barton, F.E. “Green” composites from renewable resources: Preparation of epoxidized soybean oil and flax fiber composites. J. Agric. Food Chem. 2006, 54, 2134-2137. [CrossRef] [PubMed]

30. Silva, F.D.A.; Chawla, N.; Filho, R.D.D.T. Tensile behaviour of high performance natural (sisal) fibers. Compos. Sci. Technol. 2008, 68, 3438-3443. [CrossRef]

31. Dey, P.; Ray, S. An Overview of the Recent Trends in Manufacturing of Green Composites-Considerations and Challenges. Mater. Today Proc. 2018, 5, 19783-19789. [CrossRef]

32. Cestari, S.P.; Freitas, D.F.S.; Rodrigues, D.C.; Mendes, L.C. Recycling processes and issues in natural fiber-reinforced polymer composites. In Green Composites for Automotive Applications; Elsevier Ltd.: London, UK, 2019; pp. 289-297.

33. Ramzy, A. Recycling Aspects of Natural Fiber Reinforced Polypropylene Composites. Ph.D. Thesis, Clausthal University of Technology, Clausthal-Zellerfeld, Germany, 2018.

34. Cicala, G.; Tosto, C.; Latteri, A.; La Rosa, A.D.; Blanco, I.; Elsabbagh, A.; Russo, P.; Ziegmann, G. Green Composites Based on Blends of Polypropylene with Liquid Wood Reinforced with Hemp Fibers: Thermomechanical Properties and the Effect of Recycling Cycles. Materials 2017, 10, 998. [CrossRef]

35. Deepa, B.; Pothan, L.A.; Mavelil-Sam, R.; Thomas, S. Structure, properties and recyclability of natural fibre reinforced polymer composites. In Recent Developments in Polymer Recycling; Fainleib, A., Grigoryeva, O., Eds.; Transworld Research Network: Kerala, India, 2011; pp. 101-120.

36. Weetman, C.A. Circular Economy Handbook for Business and Supply Chains: Repair, Remake, Redesign, Rethink; Kogan Page Publishers: London, UK, 2016; p. 18.

37. Lee, S.M. Reference Book for Composites Technology; Technomic Publishing Company: Lancaster, PA, USA, 1989.

38. Maya, M.G.; Soney, C.G.; Thomasukutty, J.; Sreekala, M.S.; Sabu, T. Mechanical properties of short sisal fibre reinforced phenol formaldehyde eco-friendly composites. Polym. Renew. Resour. 2017, 8, 71-78. [CrossRef]

39. Prat, D.; Wells, A.; Hayler, J.; Sneddon, H.; McElroy, C.R.; Abou-Shehada, S.; Dunn, P.J. CHEM21 selection guide of classical-and less classical-solvents. Green Chem. 2016, 18, 288-296. [CrossRef]

(C) 2020 by the authors. Licensee MDPI, Basel, Switzerland. This article is an open access article distributed under the terms and conditions of the Creative Commons Attribution (CC BY) license (http://creativecommons.org/licenses/by/4.0/). 